


\title{
The Chrysalis Project
}

\author{
By Joachim Frank
}

(Chief Guest at IIIT Delhi Convocation on September 26, 2020, virtual pre-recorded address)

\section{Abstract:}

A convocation speech of Dr. Joachim Frank (Columbia University), alumnus of the University of Freiburg, to the students of the Indraprastha Institute of Information Technology (IIIT) Delhi on September 26, 2020. The author expresses concerns regarding the current pandemic and suggests that this might be a good opportunity to rearrange the world, rather than going back to normal. 


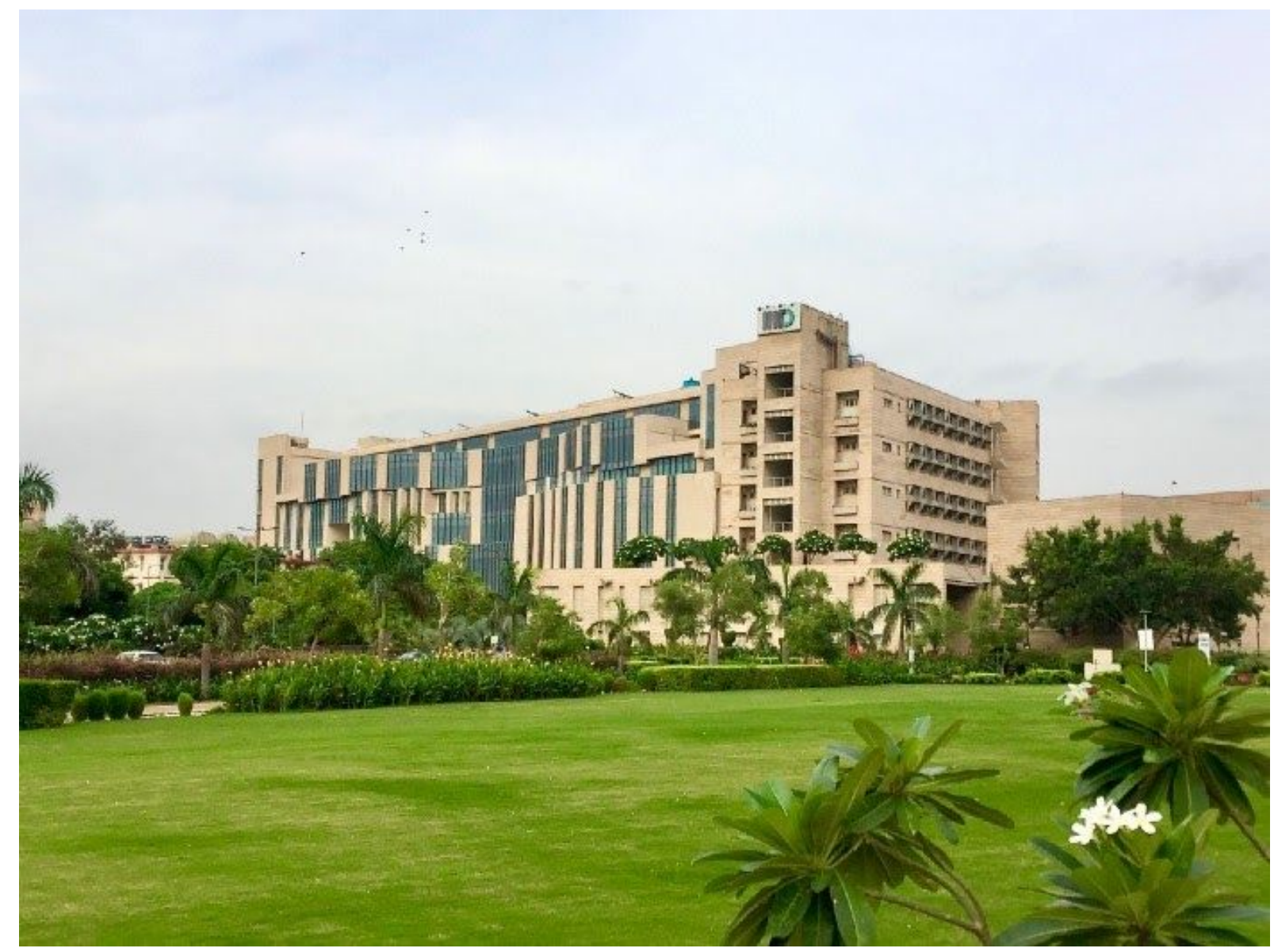

Honorable Chancellor, honorable Chairman of the Board of Governors, honorable Director of the Institute, distinguished members of the Senate and Deans of the Schools. Dear graduating students, parents and guests:

It gives me great pleasure to follow Director Dr. Bose's invitation and address you at this very important event, albeit remotely and not in real time.

In January of this year I was Chief Guest at the convocation of the Indian Statistical Institute in Kolkata and afterwards had the opportunity to personally meet with faculty, students and parents. This visit now seems years ago since the intervening events have had an effect on the flow and the perception of time. These are events that are having a pronounced effect on the world we live in. Addressing students at this important milestone in their career as scientists and engineers now, 
in September 2020, feels quite different from addressing them at the beginning of this year, simply because - as it is dawning on all of us across the globe -- the world we live in has changed in a profound way. I do not have to go through the long list of changes as we surely all have been following the galloping news on a daily basis.

We have two choices: despair at the overwhelming chaos in the wake of the pandemic, or take it as an opportunity to rethink, in a radical way, the state of affairs and the way things should be run. As someone who has experienced utter chaos once before, at the beginning of his life during World War II, and then experienced the return to civil order, decency and prosperity in Germany, my country of birth, I'm biased toward the second choice.

This brings me to a vision I had in March of this year when the reality of the virus first struck in the United States. Chrysalis, or pupa, stands for an intermediate state in the life of an insect such as a butterfly, a state of metamorphosis in which all components of the previous incarnation are scrambled, to be put to a different use. All organs of the caterpillar are dissolved into viscous protoplasm, or, on the molecular scale, into a large quantity of re-usable modules, which are contained like a soup in a hard-skinned chitin box that allows them to be re-shuffled, re-used, and rebuilt into something totally different. Baby butterfly wings - sometimes visible from the outside -- are being built right inside the middle of the soup from components that were part of the caterpillar. From all that chaos, eventually, the imago assembles, the final adult form of the insect. 
The process is amazing all in itself as a self-organized, self-propelled process of life. It particularly fascinates me as a structural biologist, who has spent his life looking at some of the pieces at high resolution with the electron microscope. But the process is also useful as a powerful metaphor, as a recipe for bringing about change. I call it the "Chrysalis Project."

The term Chrysalis, applied to world affairs, would likewise entail a complete re-ordering and re-assembling, using all material that existed before, but this time using it smartly. And instead of a revolution, starting from scratch as it were, we ideally would have a smooth negotiated transition from the deplorable state of affairs we had before, to a rational "adult" world order, where resources are shared by all of humanity and decisions are made by some kind of mechanism that gives everybody who cares an equal voice.

What are the re-usable modules swimming around in the Chrysalis soup in this metaphor? Well, we have advanced $21^{\text {st }}$ century technology, we have human resources, brilliant minds; most importantly, we have people across the globe who overwhelmingly favor peace over divisive strife and warfare among nations.

But what would be the mechanism for creating this magic smooth transition? Perhaps here we need the help of political scientists to elaborate on this vision. At the outset the idea poses a conundrum: all current government authorities would have to yield to some higher authority that everybody agrees on for implementing a new world order in the crucible of Chrysalis, but at the moment this is achieved, that 
authority would have to withdraw and disperse and let the process it has set in motion finish and flourish until the imago, the adult butterfly world emerges.

I'm not alone with such ideas of renewal. Coincidentally, as I was starting to think along the lines of the Chrysalis metaphor, I was contacted by Prof. Aurélien Barrau, an astrophysicist at the Grenoble-Alpes University in Switzerland. He asked me and 200 other scientists, intellectuals and artists to sign a plea not to go back to business as usual. My signature put me in the illustrious company of Robert de Niro, Madonna, and Cate Blanchett. The piece was published by Le Monde on May 6 under the title "A call not to go back." Here is a quotation:

“. . . along with the urgency of renewing with a politics of social equity, we believe it is unthinkable to "go back to normal". The radical transformation we need - at all levels - demands boldness and courage. It will not take place without a massive and determined commitment. We must act now. It is as much a matter of survival as of dignity and coherence."

When you applied for admission to this institute, and subsequently when you got accepted, you undoubtedly had dreams about a particular career among a wide range of careers, or you cherished the idea of being able to choose at the time of graduation. With your knowledge, expertise and certified credentials that you expected to receive today, the world would be wide open to you. Now, as a consequence of the pandemic, some of these career choices have come to naught because the economy has changed, other priorities have emerged that demand training in different trades, and travel restrictions may have created insurmountable barriers. Yet, on the other hand, entirely new choices are opening up in unexpected 
ways. As we all must take the pandemic as a wakeup call for the necessity of global cooperation, you all need to realize that your choice of career is a point where you can make a difference, a point that requires careful thought about your place in the world community and your aspirations as a responsible human being.

We don't need more weapons; what we need is technology that eases or eliminates human suffering from poverty, malnutrition, and disease. As you may know, the technology I helped create decades ago now gives us atomic structures of viruses and knowledge on a host of other molecular structures that helps in combating disease. We don't need software that accelerates trading in financial futures and further contributes to the lopsided distribution of wealth, what we need is a way to extend credit to thousands of people that want to make a living as independent farmers or small business entrepreneurs. We need smart engineering solutions to the water crisis world-wide and, most important of all, we need to address the challenge of global warming, the crisis that increasingly makes this planet uninhabitable.

These are all goals that - I firmly believe -- are achievable with today's technology and manpower, but they require intelligent and honest leadership, good will, mutual trust, and world-wide cooperation on a scale that has not existed before. I have a strong sense that with few exceptions, the new generation - your generation -- has a new mind set that is bewildered by the concept of nation states, confused by their artificial borders and visa travel restrictions, and appalled by the quarrels they have inherited from generations before. Softening these boundaries, easing these restrictions, quenching these quarrels, and building a new world cooperatively will come quite naturally to you. 
I would like to conclude on a more personal note. The most important gift you have received from your school, as I received from mine some 50 years ago, is the gift of analytical, independent, critical thinking. The fact that a majority of people share a certain belief doesn't make it right. Science history is full of cases where a single individual was right and everyone else was wrong. History itself is full of examples where people uncritically followed leaders into the abyss.

You should employ this gift of critical thinking in every situation where your instinct tells you "Wait a moment! Something is wrong here!" As a physicist I'm used to checking sum-of-digits in a calculation, or check of dimension in an equation. It is a habitual fact-checking routine of the mind. In the same vein, I want you to make fact- and rationality- and ethics-checks routinely, as you go out into this new, complicated world, a world that we will have to jointly re-build for the survival of the coming generations.

With this I wish to congratulate you for all your achievements for which you are being honored today. I congratulate your parents, many of whom will be here today, for having a daughter or son to be proud of on this very special day! I wish you all the best! 


\section{About the author:}

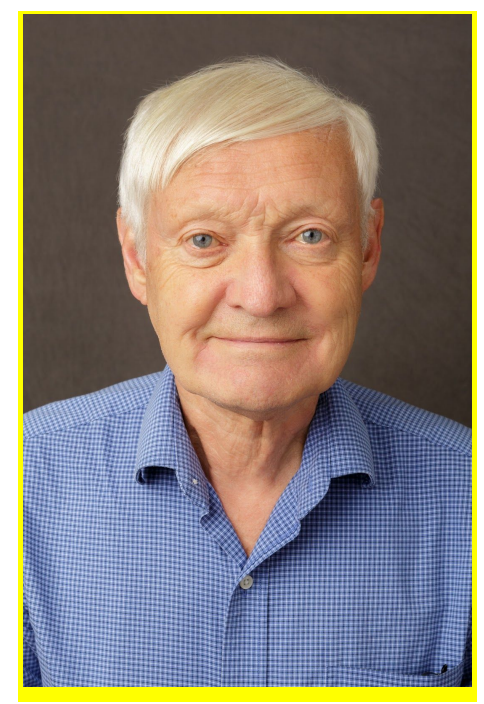

\section{Joachim Frank}

Joachim Frank is a Professor of the Department of Biochemistry and Molecular Biophysics, and the Department of Biological Sciences at Columbia University. He studied Physics at the University of Freiburg and received his Ph.D. from the Technical University in Munich. In 1975 he joined the Wadsworth Center in Albany as a Senior Research Scientist. In 1985, he joined the faculty of the Department of Biomedical Sciences of SUNY Albany. In 2008 he moved to New York to assume his current position. Dr. Frank's lab has developed techniques of single-particle reconstruction of biological macromolecules using the electron microscope, specializing in mathematical and computational approaches. He has applied these techniques of visualization to explore the structure and dynamics of the ribosome during the process of protein synthesis. They are now widely used to study the structure of the COVID-19 virus and other pathogens and biomolecules implicated in human diseases.

Dr. Frank is a member of the National Academy of Sciences and of the American Academy of Microbiology. He is also a fellow of the American Academy of Arts and Sciences and of the American Association for the Advancement of Science. In 2014 he was honored with the Franklin Medal for Life Science. In 2017 he shared the Wiley Prize in Biomedical Sciences with Richard Henderson and Marin van Heel. He was awarded the 2017 Nobel Prize in Chemistry together with Jacques Dubochet and Richard Henderson. 